\title{
San Alejo, La Unión: imaginarios, memoria colectiva y discursos de la herencia afrodescendiente
}

\author{
José Heriberto Erquicia Cruz' \\ Martha Marielba Herrera Reina² \\ Wolfgang Effenberger López ${ }^{3}$ \\ Recibido: 12/07/2013 - Aceptado: 21/08/2013
}

\section{Resumen}

El último censo nacional de población, llevado a cabo en 2007 en El Salvador, enumeró un total de 7.441 salvadoreños identificados como "negros de raza". Dicho conteo muestra la existencia de una comunidad afrosalvadoreña que se niega a desaparecer, a pesar de las décadas de rechazo de la que ha sido objeto, como colectividad étnica, por parte del Estado salvadoreño. Si bien el proyecto de 'blanqueamiento' mental, social y cultural se desarrolló con éxito, en muchos poblados del territorio salvadoreño, como San Alejo, en el departamento de La Unión, la población reconoce desde un mundo subalterno la presencia de afrodescendientes, evidenciándolos en la tradición oral, la religiosidad y la mitología, las cuales sustentan el arribo y distribución geográfica de los afrodescendientes en la zona y sus alrededores. Esta presencia étnica está generalmente asociada a agentes negativos y a una simbolización originada desde la época colonial, que se ha mantenido vigente en el imaginario social no solo de San Alejo, sino de muchos poblados del territorio salvadoreño.

\section{Palabras clave}

Religión y cultura-San Alejo-La Unión, El Salvador-vida social y costumbres, negros-El Salvador-vida social y costumbres, afrodescendencia.

\section{Abstract}

The last national population census conducted in 2007 in El Salvador, listed a total of 7.441 Salvadorans identified as "black race" ethnic origin. This count shows the existence of a community of afro-Salvadorans that refuses to disappear, despite the decades of denial that they have been subjected to, as ethnic community, by the Salvadoran government. While the mental, social and cultural whitening project developed successfully, in many Salvadoran villages such as San Alejo, people recognize from a subjacent world the presence of afro-descendants, showing them in oral tradition, religion and mythology which support the arrival and geographical distribution of African descendants in the area and its surroundings. This ethnic presence is generally associated with negative agents and symbolization originated from the colonial era, which has been kept alive in the public imagination not only of San Alejo, but of many villages of El Salvador.

\section{Keywords}

Religion \& culture-San Alejo, La Union, El Salvador-social life and customs, black-El Salvador-social life and customs, african descendents.

1 José Heriberto Erquicia Cruz. Es licenciado. en Arqueología y Maestro en Ciencias Sociales. investigador. Universidad Tecnológica de El Salvador. jose.erquicia@utec.edu.sv

2 Martha Marielba Herrera Reina. Es licenciada en Antropología. Co-investigadora. Universidad Tecnológica de El Salvador. marielba@gmail.com

3 Wolfgang Effenberger López. Es Máster en Antropología. Co-investigador. Universidad Tecnológica de El Salvador. w.effenberger@googlemail.com 


\section{Introducción}

En el presente, para la gran mayoría de salvadoreños, en este país no existen y nunca han existido personas de ascendencia africana. Sin embargo, el último censo nacional de población llevado a cabo en 2007 enumera a 7.441 salvadoreños como "negros de raza", ya sea porque estos se autodenominaron así o no. Lo que queda claro es que existe una población que se autodefine como descendiente de africanos. Recientemente, la ONU ${ }^{1}$ declaraba a 2011 como Año Internacional de los Afrodescendientes. Justo a partir de ello, el Estado salvadoreño, a través de la Secretaría de Cultura de la Presidencia e instituciones como la Procuraduría para la Defensa de los Derechos Humanos y otras representaciones de la ONU en El Salvador, se dieron a la tarea de "indagar" en el asunto de los afrodescendientes salvadoreños.

Desde las ciencias sociales se ha comenzado a cuestionar sobre ¿quiénes son estos afrodescendientes? ¿qué hacen?, ¿en qué condiciones se encuentran?, y otras preguntas que ayuden a comprender las diferencias de la heterogénea sociedad salvadoreña.

Numerosos discursos surgieron con el enfoque a la pregunta de ¿qué nación debería ser construida y en qué país querían vivir los salvadoreños? Estas inquietudes señalan un proceso de construcción de nación en el cual El Salvador está inmerso. Naciones e identidades nacionales son procesos dinámicos, que están moldeados por diferentes momentos claves a lo largo de la existencia de un país (Acuerdos de Paz, cambios de gobierno, revoluciones, entre otros hechos).

La construcción de una nación está vinculada al contexto internacional. Si las naciones, desde el siglo XIX, se imaginaban y construían a partir de un modelo y proyecto de nación homogeneizador, los países latinoamericanos, a partir de los siglos XX y siglo XXI, tienden a visibilizar, en distintos grados de intensidad y voluntad, desde la sociedad civil y desde el Estado, su diversidad cultural y étnica.

A la luz de la importancia que disciplinas como las de Historia y Antropología tienen en los estudios culturales y sociales, es trascendental asumir el reto de contribuir desde los espacios académicos a la construcción de una nación más incluyente, étnica y culturalmente heterogénea, y diversa.

Por consiguiente, a partir de indagaciones como los imaginarios y discursos de la memoria colectiva de una determinada comunidad, la historia o narrativa de la nación se diversifica y evidencia la particularidad de las regiones que constituyen un país. De esta manera no solamente se fortalecen las identidades de las localidades, sino también las identidades de El Salvador desde una visión global que se (auto) reconoce. Con ello, se pretende que estos enfoques conlleven, a corto y a largo plazo, a reconocer los aportes y derechos económicos, políticos, sociales y culturales de los afrodescendientes de El Salvador.

El objetivo de la investigación recayó en lograr identificar y documentar la herencia africana en la población de San Alejo, La Unión, a través de una exploración etnográfica que describiera el imaginario y los discursos de las identidades locales.

Para lograr dar respuesta a la problemática planteada en esta investigación, se generaron varias preguntas que permitieron acercarnos a la realidad sociocultural actual de las personas afrodescendientes de San Alejo, las cuales fueron orientadas a expresar: ¿Cómo la herencia africana ha configurado la identidad de los pobladores de San Alejo?, ¿cuáles son los conflictos a los que se enfrentan los pobladores que se asumen afrodescendientes en San Alejo? ¿cuáles son los elementos socioculturales representativos en la comunidad afrodescendiente en San Alejo? y ¿cuáles son las implicaciones que tiene un poblador de San Alejo que se autodefina como afrodescendiente?

"No existe verdadero acto de memoria que no esté anclado en el presente", afirma Jochen Gertz (Citado en Candau, 2006; p. 95). La memoria histórica es prestada, escrita, aprendida, pragmática, larga y unificada; en cambio, la memoria colectiva es una memoria vívida, oral, normativa, corta, plural y producida (Halbwachs; citado en Candau, 2006). La sociedad produce percepciones fundamentales por analogías, por vínculos entre lugares, ideas, personas y demás, los cuales estimulan recuerdos que pueden ser compartidos por muchos individuos e incluso por toda la sociedad (Candau, 2006).

Como afirma Edelman (Citado en Candau, 2006; p. 63): "LOS mitos, las leyendas, las creencias, las diferentes religiones son construcciones de las memorias colectivas". Es por ello que, a través de los mitos, los miembros de una colectividad buscan traspasar una imagen de su pasado de acuerdo con su propia interpretación de lo que ellos se consideran que son.

Para el caso de los afrodescendientes, a pesar del discurso del Estado de negación y olvido, dentro de la memoria colectiva, en diferentes generaciones, se presentan relatos

1 ONU: Organización de las Naciones Unidas. 
que vinculan directamente a este grupo étnico con aspectos sociales y religiosos cotidianos que deben ser desentrañados y puestos en discusión en la misma comunidad para reforzar los conceptos de diversidad que implican la tolerancia, la inclusión, el respeto, los derechos humanos, entre otros aspectos.

\section{Metodología de la investigación}

En el abordaje de la presente investigación se utilizó el método etnográfico, que permitió conocer la información de primera mano de los pobladores de San Alejo, tanto del área urbana como rural, a partir de entrevistas semiestructuradas focalizadas, en un entorno de confianza en el que los entrevistados pudieran profundizar en las preguntas que se les plantearon, con miras a obtener más información. Por medio de esta técnica, se construyó un instrumento donde se abordaron los tópicos de interés en la búsqueda de respuestas del problema de investigación (Vela Peón, 2001). En algunos casos, se ampliaron las preguntas debido al tipo de información que los entrevistados brindaron en relación con la temática abordada; por ejemplo, mitologías, tradición e historia orales, entre otros aspectos.

La investigación desarrolló un total de 23 entrevistas a informantes de San Alejo, de las cuales 9 corresponden a personas que viven en el área urbana (6 hombres y 3 mujeres); mientras en el área rural se entrevistó a 14 personas ( 9 hombres y 5 mujeres). Durante la temporada de campo de registro de las fiestas patronales en honor a San Alejo, se abordó a un aproximado de 40 estudiantes de tercer ciclo del Instituto Nacional, en el que se recopiló información que ellos conocían de la tradición oral relacionada con las costumbres, la mitología y las creencias del municipio de San Alejo. De igual manera, se recopiló un aproximado de 15 jóvenes de la pastoral "Monseñor Romero" del templo católico de San Alejo, quienes ofrecieron datos importantes acerca del significado de ser afrodescendiente en San Alejo.

\section{Resultados de la investigación. Creencias y religiosidad sanalejense}

La vida de los pobladores de san Alejo no se desliga de la religiosidad cristiana popular, en ella son numerosas las alusiones en cotidianidad que reflejan ese vínculo con lo sagrado. Estas expresiones religioso-culturales se identifican además con las historias locales que forman parte de la mitología vinculada a hechos históricos que probablemente se originaron a finales del siglo XIX. Estas características se pueden evidenciar en cada uno de los relatos compilados en la población de San Alejo, ya sea desde lo sagrado, lo festivo de la tradición y las fiestas a los patronos, así como creaciones y asociaciones de las imágenes y milagros realizados por estas ante acontecimientos sociales, políticos y económicos, que a lo largo del tiempo ha sufrido esta comunidad en el oriente de El Salvador. Este es un factor determinante en el imaginario local debido a que da origen a las pautas de identificación de una comunidad con otra; no es difícil identificar en cada cantón o caserío una gruta o ermita a un santo patrono local, más allá del patrono del municipio.

Una leyenda relacionada con la historia local sanalejense se refiere a que, en el año 1969, para la guerra de El Salvador con Honduras, la población católica se avocó al templo para pedir al Señor de los Milagros y a san Alejo que los salvara de los ataques y que protegiera al pueblo. Un día, el sacristán abrió las puertas de la iglesia y los fieles entraron a orar; cuando buscaron al Señor de los Milagros en su nicho, san Alejo no estaba. Sus creyentes dicen que este había escuchado sus oraciones y se convirtió en soldado. Patrullaba las orillas del pueblo, y, una vez terminada la guerra, el patrón regresó a su nicho; por eso es que no le pasó nada al lugar, debido al milagroso personaje. Las historias relacionadas con el santo patrono, además de tener una connotación religiosa, se mantienen vinculadas a un aspecto militar, que le adjudican a san Alejo. Esta misma visión ha configurado la identidad de los sanalejenses, que la refuerzan a partir de las historias relacionadas con la religiosidad y los hechos históricos particulares, reales 0 supuestos, como la Independencia, la guerra de 1969 con Honduras, el involucramiento de santos para detener alguna catástrofe, una guerra, entre otros acontecimientos que generan una pertenencia común y que implican la relación directa de las imágenes religiosas con el imaginario local.

Un culto poco conocido se celebra durante la primera semana del mes de noviembre en el caserío El Crucillal. Festejan en honor a san Martín de Porres. Este es conocido también como el prim er santo negro de América. En ese universo religioso sanalejense, el culto a Martín de Porres sigue latente, aunque no todos conocen de él. En las entrevistas realizadas se pudo constatar que las festividades realizadas en su honor se hacían aún a inicios del siglo XX. Reconstruir la tradición olvidada permite relacionarla directamente con los afrodescendientes en ese siglo. Probablemente desde el año 2005 se reactivó la tradición y el culto a Martín de Porres; sin embargo, tal como se maneja en la tradición oral, se le festejaba en el cantón Piedra Gorda, donde muchos identifican en el discurso cotidiano que es allí donde se puede encontrar "gente negra". 


\section{Culturales subterráneas, historias orales, mito, geografía y presencia africana en San Alejo}

Para los sanalejenses, la geografía de sus alrededores, como el volcán Conchagua y otros cerros circunvecinos, forma parte del imaginario, como "guardiana". Es por ello que aquellos son elementos indispensables de los archivos de la memoria histórica local. Ese imaginario está representado en los cerros La Juana Pancha, La cuesta, Pregúntame, Conchagua, Mogote y el volcán El Capitán, entre otros. La percepción de la naturaleza y los paisajes se inscribe en la cultura narrativa. Así, para Bachmann-Medick (2004), los signos y los textos del paisaje marcan momentos de la memoria colectiva. Memorias cuyas voces no están inscritas en documentos, sino más bien en su entorno concreto.

Uno de los informantes del cantón Lagartón muestra una parte del mundo mitológico de San Alejo cuando comenta que, en un lugar en donde se encontraba un árbol de amate, o matapalo, a este "lo quemaron, hace siete años, porque el árbol asustaba". Así, para resistir al árbol encantado, un vecino lo quemó, y desde ese entonces "ya no asustan en ese lugar". Es así que se evidencia la matanza de un árbol encantado, porque en este vivía un espíritu que se aniquila con su quema. Con ello, desaparece; y todo se solucionó con un acto violento. Sin embargo, al parecer, los encantos siguen vigentes. Traducido a un contexto "poscolonial", la cristianización, a la vez diabolización de la cosmovisión animista, todavía se lleva a cabo, con prácticas que recuerdan enfrentamientos crueles. Esto recuerda a las prácticas de destitución violenta de las religiones ancestrales. No existen arboles encantados, o no deben de existir. El mundo animado, la fauna y la flora, que en sus entrañas viven seres humanos, extrahumanos, está en un proceso por desaparecer o transformarse.

Las relecturas de historias y leyendas son el resultado de un posible legado africano, ofrecidas, como arqueólogos, desde una visión que permite ver los cambios de los hechos o procesos históricos a lo largo del tiempo, vinculando los residuos y fragmentos de africanos en la sincronicidad del pasado. De la misma manera, para entender los mitos históricos en la actualidad, el historiador emprende un viaje en el tiempo, insertándose en la realidad, en el San Alejo colonial; allí en donde se encuentran los negros, los mulatos, los mestizos, los indígenas y los criollos en su diversos papeles y funciones y visiones de mundo. Es por ello que, a partir de esas translocalizaciones, se aproxima a la interpretación de las narrativas.
Así, a la luz de la presencia afrodescendiente en San Alejo, se aplica una lectura arqueológica; se remonta al pasado colonial; se observan las huellas y se escuchan las voces de la población mulata de inicios del siglo XIX. Se conversó con piratas negros de los siglos XVII y XVIII; se reimaginarán los arrieros de ganado, descendientes de africanos esclavizados. Con este diálogo se abre una metodología nueva al analizar la oralitura salvadoreña y, como tal, se siguen los planteamientos enunciados por el escritor afrocostarricense Quince Duncan (2005) en su artículo "El afrorrealismo. Una dimensión nueva de la literatura latinoamericana".

La doble identidad africana e indígena, o "confusión", fue escuchada muchas veces durante las visitas a San Alejo. Más que de una presencia negra o afrodescendiente, se hablaba de una presencia indígena. Algunas veces, después de comparaciones, se detecta que indio es sinónimo, sin querer o sin recordar conscientemente, de negro. En un país en el cual se niega la presencia negra, estos se convierten en "indios". Tanto los negros como los indígenas son los otros de la sociedad, y así su sustitución recíproca practicable; ausencia en el presente y mitificación en el pasado; seres que viven en esferas invisibles, en mundos subterráneos. Sin embargo, existen diferencias entre ellos.

La mitogeográfia archiva acontecimientos que entrelazan diversos tiempos-espacios que pueden ser interpretados a través de la convergencia entre mito y realidad, o mitorealidad. Sin embargo, la cuenta del tiempo y su concepción es un ejercicio cultural y múltiple; igualmente las posibilidades que se atribuyen a los movimientos en el espacio o tiempoespacio.

Inscrito en otra elevación geológica, además del cerro El Capitán, es un texto que fue plasmado en una recopilación de la tradición oral de la ciudad de San Alejo realizado por el personal de la Casa de la cultura en el año 2003. El cerro que interesa es el denominado La Juana Pancha, que se ubica al sur, a unos 7 kilómetros del casco urbano de San Alejo. En la mencionada monografía se encuentra una narración que habla sobre la "bruja" Juana Pancha. Traduciendo el saber popular, se puede atribuir a ella lo que comentó un narrador que antes, "había gente sabía. Juana Pancha sabía, era una persona que sabía. Lo que sabía... es lo siguiente: ella habitaba en una cueva del cerro. La mujer se llamaba Juana Francisca Callejas, y se dedicaba al espionaje $y$ al robo. En sus robos le ayudaron sus conocimientos de artes mágicas: viajes en el aire, disminuciones de su cuerpo, invisibilidad, etc.". La tradición oral transcrita explica que ella se transportaba instantáneamente de un lugar al otro. Según la narrativa, "se elevaba en un globo formado por cascarones de huevos y se conducía al recinto ubicado 
en el palacio de los Capitanes Generales' de la antigua Guatemala" (Flores y Masera, 2010; p. 20). Igualmente, Juana Pancha está ligada a La cuesta de Pregúntame, y desde donde ella controlaba a la gente que transitaba a San Miguel. Resulta que en Guatemala fue capturada a través de una conspiración entre otros hechiceros y sacerdotes. Su testamento se quedó en Guatemala. El día de su muerte, "el Mandinga se constituyó en el calpián del cuantioso caudal. Por eso la cueva se encuentra encantada. Si alguien, por casualidad, da con ella, no la vuelve a ver nunca" (Flores y Masera, 2010; pp. 20-21).

Volviendo a las narrativas sanalejenses, se deducen dos momentos al comparar las fuentes hasta ahora consultadas. El Mandinga es un diablo negro aliado de Juana Pancha que guarda el tesoro dentro de una cueva. En ese sentido, repite la figura de los africanos (piratas) cuidando los tesoros. Por otra parte, se observa la diabolización de una etnia negra. La traducción de mandinga: "diablo", en vez del pueblo "Mande", evoca el momento de las violencias simbólicas en el contexto de la colonización y esclavización que se formaron a la par de las violencias militares (Castro Varela y Dhawan, 2005). Se percibe, a través de los relatos anteriores, más bien la cercanía del golfo como ente clave en el desarrollo de San Alejo. En otras palabras, de una cultura pirata como parte de una memoria clave en San Alejo. Asimismo, se constituye la presencia en un eje importante para el desarrollo y la experiencia social, cultural y económica. En ese medio, se plasma la presencia y el papel en los relatos de seres negros ligados sobre todo al "mal", al "diablo", vinculados a las cuevas, la riqueza y a la ganadería.

Relatos de la época colonial de la primera mitad del siglo XVIII mencionan que la hacienda de San Alejo del Pedregal, se dedicaba, a la par de producir cereales y añil, a la crianza de ganado (Lardé y Larín, 2000). Los que trabajaban en las haciendas como vaqueros fueron en su gran mayoría blancos pobres, negros esclavos, mestizos y mulatos libres, pero muy pocos indígenas (Escalante Arce, 1994).

En las narraciones que se interpretarán a continuación aparecen los vaqueros, el ganado, los cerros, los dueños del monte, los pactos con el diablo y los jinetes negros, cuyas actividades registran experiencias muy parecidas a las actividades de los vaqueros mulatos de la época colonial. Los seres que aparecen en los relatos comparten características, de una manera que se podría pensar que se trata de la misma entidad. Sin embargo, las narrativas orales siguen sus propias maneras de crear y reproducir su contenido, creando una asamblea de seres extrahumanos y desdoblamientos. Así, el Diablo se asemeja al Partidario, el Partidario al Duende, el Duende al Caballero de la noche, y el Caballero Negro al Diablo; y todos estos seres se constituyen como los "Dueños del Monte", o habitan el volcán cuyo origen se encuentra en la antigua concepción precolombina del Señor de la tierra (López Austin, 1996).

Entre el campesinado de San Alejo, el duende aparece en visiones, en sueños y augurios. Existe una cultura de prever el futuro e integrar visiones en la cotidianeidad. El Duende se convierte en el Dueño del monte, Señor de la tierra, que cuida a los animales y que los entrega a los cazadores; sin embargo, bajo ciertas condiciones, no más. También el Duende ejerce poder sobre el ganado, y es él quien asegura abundancia y reproducción. También tiene el poder y el conocimiento de penetrar en la consciencia del ser humano a través de sueños y visiones.

\section{De lo biológico a lo social: percepciones de la diversidad étnica en San Alejo}

"Ser negro es cuestión de piel", expresaba una de las personas entrevistadas para esta investigación cuando se le preguntaba cómo se podía distinguir a este grupo de individuos respecto a otros. Así como esta, en la mayoría de los casos, el ser negro, indígena, chino, blanco o pertenecer a otro grupo étnico, se ve reflejado por los demás a partir de los rasgos y características fenotípicas.

Cuando llegaba a su fin la administración colonial, de la cual formaba parte San Alejo como Partido de la Intendencia de San Salvador, e iniciaba la construcción de un nuevo Estado a inicios del siglo XIX, entre 1814 y 1819 , se documentaba en el libro de bautizos de la parroquia del pueblo con las categorías étnicas de mulatos, indios y españoles. Sin embargo, ya en 1820, con el cambio de párroco -que jugaba el papel de censor-, esas categorías empezaban a desaparecer y a ser más difusas. Con ello aparecía la categoría social de ladino, la cual llegaría a formar la mayoría de los pobladores de San Alejo, mucho más que mulatos, indígenas y españoles. Este hallazgo del cambio de percepción del párroco de la iglesia de San Alejo, en cuanto a la adscripción étnica de sus feligreses, muestra cómo son de frágiles las categorías étnicas, pues estas se estaban dando a partir de la percepción de una persona que, en este caso, tiene el poder de decidir en dónde encasilla a los habitantes de determinado lugar.

A continuación se muestra un segmento de la población de San Alejo, según las actas de bautismo del año de 1815. 
Tabla 1.

Libro de registro de actas de bautizo de la parroquia de San Alejo (enero a diciembre de 1815)

(En dicho total están contabilizados hombres, mujeres e infantes designados según el acta de bautizo)

\begin{tabular}{lcc} 
Población étnica & Totales & Porcentajes \\
\hline Mulatos libres & 402 & 94,81 \\
Mestizos & 6 & 1,41 \\
Indígenas & 5 & 1,19 \\
Españoles & 4 & 0,94 \\
No clasificados & 7 & 1,65 \\
Total & 424 & 100 \\
\hline
\end{tabular}

Fuente: Libro de registro de actas de bautizo de la parroquia de San Alejo, 1815.

El tema de la herencia africana es complejo. Por ello, cuando en la consulta se les preguntaba ¿hay negros en San Alejo?, un entrevistado afirma que "sí, un montón de negros. Fíjese que estos cipotes míos son bastante negros, mi papá era negro y mi mamá era más chelita (...). En la familia de nosotros hay bastantes negros (...). Fíjese que el señor que vive aquí enfrente, ese señor es azul (...) Asimismo, marca una diferencia al decir que, "el negro es diferente hasta para el modo de caminar...". Otro de los consultados apreciaba que, "solamente aquí en el barrio le puedo enseñar como a cien negros (...); y luego acotaba que, "yo me considero negro, más negro que blanco". Esta misma persona evocaba características positivas de los negros hombres, diciendo que estos son buenos para trabajar; pero también, si no trabajan, los critican. Además decía que, "el moreno es más capaz, más fuerte, para jugar y para las mujeres".

¿Dónde están esos negros? era la pregunta obligada a los encuestados. Con ello, las respuestas eran diversas: "Aquí [en San Alejo] abundan los negros; los cheles son de Santa Rosa y Corinto (...); los negros están dondequiera; [son] negros que relumbran...". Además, comentaba la historia del nacimiento de su nieto, pues cuando vio a su nieto, que era moreno, dijo: "Qué iba a ser, pues, sí el cipote [el papá del recién nacido] es negro, así como esa jarrilla [jarra, la cual está completamente cubierta por el hollín de las brasas de la cocina de fuego de leña]. Donde quiera hay negros, en la mayoría de los cantones de San Alejo, en el cantón El Retumbo; [y otros como] Agua fría, es el cantón que tiene más negros...". Esta misma persona decía: "Hay revueltos. Hay negros, y todos colochos,' les dicen 'chochos.'. ${ }^{3}$ Casi que

2 Colocho se refiere a alguien que tiene el cabello rizado.

3 Chocho es también un apodo con el cual se denomina a los nicaragüenses. por todo el territorio [de San Alejo] hay negros; tengo nietos chirizos y colochos, y todos negros".

Otras de las consultas hechas fue: ¿Existe descendencia africana aquí en San Alejo? Con ello, un consultado expresaba: "No, no, no, [aquí no hay negros], aquí solo uno que es de Colombia. Colombia le dicen. Solo ese hay aquí, y él es jugador [de fútbol]. Negros, negros, no [hay], solo del color mío [moreno]. Sí, así sí hay un montón... No hay negros. Es que el negro es negro; morenos sí hay...". Es en este sentido que se expone una negación; pero a la vez una contradicción, pues, para el caso del entrevistado, imagina a los afrodescendientes o negros estereotipados, como lucen en la televisión los africanos esclavizados de Norteamérica.

Por su parte, otra persona cuestionada sobre el tema de la existencia de personas de origen africano en El Salvador afirma que, "sí hay negros, porque hay lugares que sí hay negros, pero me han platicado que sí hay en El Salvador. Nosotros ya estamos matizados (...) Se mezclaron estas familias de un lugar a otro; ya vinieron, ya de otro modo. En Bolívar [municipio del departamento de La Unión] hay gente blanca. El africano yo no lo conozco ni de atrás ni de adelante". Dicho sujeto sí cree que hay gente de ascendencia africana en El Salvador, pero cree que se han "mezclado" con otros grupos; por ende, le es difícil poder percibir cuándo una persona desciende de ese grupo étnico.

Para el párroco del templo de San Alejo, las imágenes del Cristo Negro y San Martín de Porres, que representan hombres de piel obscura, son "imágenes [que] tienen que ver con los habitantes de las regiones. Entonces el Cristo Negro se hace como para identificar a las personas...". Sin 
embargo, dichas imágenes las asocia con los pobladores indígenas y no con los habitantes afrodescendientes de la región.

Entre los entrevistados, a una mujer que se asume afrodescendiente de San Alejo se la consultaba sobre qué piensa acerca de que el Estado y el imaginario de los salvadoreños, por mucho tiempo, han negado la presencia de personas de ascendencia africana. Ella expresaba: "[Nos] decían que en El Salvador no hay afrodescendientes, es decir, que nosotros no existimos...". Dicha mujer, al asumirse ser parte de esa herencia, afirma:

"Soy afrodescendiente. Es, por ejemplo, lo que yo soy. Esta sangre que no ha desaparecido, porque todavía se va legando de generación en generación, y que no se puede eliminar. Partimos de la descendencia de otro continente. La misma raza se ha logrado mezclar, y parte de ella somos nosotros; soy yo, es mi familia".

\section{Consideraciones finales}

Desde los estudios culturales, el abordaje de las identidades étnicas es por demás una temática compleja. Es por ello que no se pretende con esta investigación dar respuesta a un sinnúmero de interrogantes que surgen al estudiar la diversidad étnico-cultural de los habitantes de un país como El Salvador, el cual, hasta ahora, se sigue mostrando como una nación homogénea, en la cual, para muchos, no tiene cabida dicha diversidad.

Es a través de investigaciones académicas que aporten a generar y crear conciencia de su presencia, así como aceptar y visibilizar a los afrodescendientes. En ese sentido, es necesario acercarse a estas poblaciones y conocer, desde sus experiencias, cuáles son las condiciones de vida en las que se encuentran, así como identificar el impacto que tiene el pensamiento colonialista de 'blanqueamiento'. Es por esto que, partiendo de los objetivos de esta investigación, se logró determinar que el discurso de negación por parte del Estado ha incidido en la conformación del imaginario colectivo, en cuanto a la identidad de los afrodescendientes en San Alejo. La pertenencia queda limitada a aspectos asociados a lo religioso, al trabajo en el campo y al deporte. Sin embargo, a la luz de las entrevistas realizadas, podemos determinar contradicciones que permiten identificar que los elementos socioculturales de este grupo étnico se mantienen en la actualidad y han sido transmitidos por generaciones, en donde la memoria colectiva juega un papel importante en la conformación del imaginario local, que de una u otra forma vincula situaciones, hechos y personajes a una historia poco conocida de los diferentes grupos étnicos que conformaron y dieron personalidad a la población de San Alejo de inicios del siglo XXI.

Tomando en cuenta esa diversidad multiétnica y multicultural, se abre un espacio para comprender las relaciones sociales que se han desarrollado en la localidad. A lo largo de la historia - y es el caso de los afrodescendientes en San Alejo-, como en muchos otros lugares, los afrodescendientes son considerados como personas inferiores e incapaces de participar efectivamente en el conjunto de la sociedad. Esto lleva a entender el porqué de la negación y de la exclusión. Dicha diversidad étnica está en permanente tensión. Los numerosos grupos étnicos se han enfrentado de manera desigual, a la luz de proporcionar sus visiones de mundo, comprender y nombrar la realidad, y mantener - para lo hegemónico- o alcanzar — para lo subalterno- el reconocimiento y la visibilización de sus espacios de poder (Albán, 2010). Estas deben ir orientadas a la autodeterminación y reconocimiento por parte del Estado. Sin embargo, deben crearse nuevos esfuerzos, desde las comunidades mismas, que proporcionen los elementos necesarios para comprenderlos y exponer las condiciones de vida en las que se encuentran, mismas que han estado sujetas a esa negación que por generaciones se ha transmitido, creando un sinfín de ideas y discursos que se manejan en la sociedad salvadoreña respecto a la negación de las comunidades afrodescendientes que históricamente fueron llevadas a una misma forma de vida, donde el poder de la palabra no se les era permitido. Sin embargo, a partir del reconocimiento se pueden generar procesos de recuperación de la presencia misma de estos grupos a través de la reivindicación y socialización de estudios que evidencien la existencia de estos dentro de la sociedad. Se trata pues, como afirma Albán (2010), de reconstruir la historia de los pueblos silenciados y enfrentar el racismo estructural que ha minimizado a indígenas y afrodescendientes. Este se vuelve un desafío para las ciencias sociales y las humanidades, porque implica descolonizar todos los ámbitos de la sociedad: Io político, social, económico, cultural, en fin, cada uno de los aspectos que se involucran directamente con el ser humano.

Por esta razón, San Alejo se convierte en un referente de las historias silenciadas de la diversidad étnica y cultural que conforma a El Salvador. En esencia, las historias encontradas en la comunidad no difieren de las que probablemente se pudiesen encontrar en otros lugares del territorio salvadoreño, sustentadas por la historia local, la tradición, la cultura y las problemáticas a las que se han enfrentado los afrosalvadoreños a lo largo del tiempo. Esas evidencias de la presencia de este grupo étnico se pueden encontrar en documentos coloniales que permiten 
abrirnos una ventana y aproximarnos a familias e individuos reconocidos como mulatos libres que habitaban el poblado de San Alejo a finales de la época colonial, mismos que ofrecen establecer relaciones entre diferentes poblados, matrimonios, nacimientos, parentescos, entre otros datos localizados en estos documentos.

Por otra parte, un elemento importante que permite establecer la presencia afrodescendiente en la cultura viva actual de la sociedad salvadoreña $-\mathrm{y}$ hasta ahora encontrado en el oriente del territorio- es la religiosidad popular que establece las relaciones entre grupos étnicos, creencias y tradiciones. Para el caso, de las imágenes negras asociadas a cultos de mulatos y afrodescendientes desde siglos pasados, entre ellos san Benito de Palermo en los departamentos de Usulután y San Miguel, y los cristos negros en los municipios de Ereguayquín y San Alejo. En este último, donde las imágenes del Cristo Negro y san Martín de Porres son las que en la tradición oral generan un vínculo directo con este grupo étnico, y que además es reconocido por generaciones de adultos y jóvenes porque sus antepasados rendían culto a las imágenes. No es casual que, en ambos casos antes mencionados, sean los patronos de estos poblados las imágenes negras asociadas a mulatos y afrodescendientes; y que la historia oficial no ha podido eliminarlas del imaginario local. Sin embargo, a la luz de las investigaciones, se muestra cómo, con el paso del tiempo, algunas de ellas van perdiendo esa relación directa con el origen del culto. Tomando en cuenta este elemento religioso, este se vuelve un generador de identidad y un vínculo de apropiación de la cultura religiosa popular de los afrodescendientes que aún habitan San Alejo. Es a través de dichas expresiones que aún se encuentran remanentes de tradiciones y cultos establecidos, desde la época colonial y la republicana, que fueron instaurados por los mulatos y que se conocen hoy en día.

Probablemente, muchas personas desconocen el verdadero origen de los cultos y rituales asociados a las imágenes negras, creadas para las poblaciones negras, como elemento generador de identidad, comunidad, convivencia, cohesión; y en algunos casos se muestra resistencia a una tradición impuesta, o, en otros, a modificar las creencias de sus antepasados y resignificarlas; para así mantener un vínculo directo con el lugar de origen, del que una vez fueron comercializados y trasladados a nuevos espacios geográficos donde tuvieron que adaptarse a un nuevo orden establecido, al que no pertenecían y en el que tuvieron que sobrevivir.

En este sentido, esa incorporación de imágenes religiosas adaptadas a su condición de africanos esclavizados, como san Benito de Palermo (hijo de esclavos manumitidos) y san Martín de Porres (hijo de español y mulata), significó el cambio de culto de un santo de origen africano asociado a la esclavitud a un santo mulato de América que, por su condición, estaba más asociado a los mulatos libres y que representaba la realidad de estos en la sociedad. Estas expresiones religiosas forman parte de la cultura salvadoreña actual, y, como en la mayoría de los casos, tienden a relacionarse con comunidades indígenas. Sin embargo, ponen en evidencia la relación afroindígena de muchas poblaciones en El Salvador. Y para el caso de San Alejo, los pobladores tienden a fusionar elementos culturales afrodescendientes con indígenas, porque, al final, gracias al 'blanqueamiento', lo indígena prevalece sobre lo africano.

Otra forma de encontrar esa presencia dentro de la comunidad sanalejense es a partir de la oralidad. Los enfoques etnohistórico y afrocéntrico permiten aproximarse a una interpretación nueva, para el caso de El Salvador y su narrativa cultural. Dicho enfoque busca la reconstrucción sincrónica de la narrativa, puesto que identifica el origen colonial de las narrativas populares, y diversas referencias, las cuales permiten realizar tal aproximación. Muestras de ello son los relatos sobre la piratería, o las referencias en cuanto al centro del poder colonial, la Antigua Guatemala.

En San Alejo aparecen diversos relatos de viajeros, pues dicha localidad se situaba en una de las zonas que recorrían, a partir de las rutas de comercio de la época colonial, en la cual estaban involucrados directamente, afrodescendientes trabajando como vaqueros. La presencia africana que evoca la tradición narrativa en su relación con los piratas está evidente en las relaciones orales. El archivo oral, como se pudo observar, se correlaciona con los registros escritos sobre la constante incursión de piratas en la región del golfo de Fonseca.

Existe una cantidad de seres cuyas experiencias concretas se convirtieron en un pensamiento de la época epistémica y colonial en seres míticos. Muchas veces, la connotación con la que se describen tales seres míticos evoca a personajes que se encuentran fuera de la ley; entre ellos, bandidos y piratas, los cuales se encuentran viviendo, refugiados en cuevas y escondites, y de los cuales se hallan omnipresentes en los relatos, cuya importancia en la cosmovisión y mundo ritual debe ser profundizado, en especial en cuanto a su relación con los pactos con el Diablo.

En ese mismo mundo y la relación con los afrodescendientes, sean estos vaqueros o trabajadores en otras actividades, habría que investigar también su legado de la experiencia de su trabajo en las minas de la región. En general, cómo 
la cultura popular categorizaba, según sus posiciones epistémicas, los hechos y las personas en la época colonial, e indagar cuándo surgieron esas narrativas.

La instalación de cabildos de mulatos para controlar las personas mulatas, descritas como bandidos, es una cita que se remonta al recuerdo de los imaginarios que construyeron los viajeros de esa época, cita que coloca a los afrodescendientes como una amenaza subversiva.

Las diferencias entre tal población, llegarían a formar las milicias de pardos o mulatos, ya sea defendiendo o combatiendo cimarrones afrodescendientes 0 bandidos (Juárez Martínez, 2005), lo cual se convirtió, muchas veces, en la manera o una vía para que, a largo plazo, estos afrodescendientes pudieran trascender los estratos sociales. La experiencia de que existían milicias en la región también está de la mano con la documentación escrita en los sustratos de las expresiones de la oralidad. Escalante Arce (1995) identifica que "la danza de los negritos" se refiere y es una expresión de las milicias mulatas; asimismo, se documentó que en el pueblo de Yayantique (contiguo a San Alejo, y que en el pasado ambos formaban parte de la misma región administrativa) se representa "la danza de los negritos".

La presencia y conjugación, entre las milicias de negros, es la presencia del Cristo Negro convertido en miliciano. En varios relatos, como se vio en los capítulos anteriores, están presentes tres defensores del pueblo, algunas veces vestidos como milicianos, que son los patronos del pueblo: san Gaspar, san Alejo y el Cristo Negro. Ellos se enfrentaron a hombres que supuestamente iban a destruir al poblado de San Alejo.

En algunos relatos las milicias foráneas venían de Yayantique, por las rivalidades que se tenían entre ellos. Y los tres caballeros (san Gaspar, san Alejo y el Cristo Negro) lograron detener el peligro de la invasión y la destrucción. Así, el santo negro se convierte en parte de la milicia de negros, defensor del pueblo y su orden. Justo en ese complejo se observa la doble significación de los negros en San Alejo, la cual gira en torno a dos ejes: la diabolización del cuerpo negro y la santificación del cuerpo negro. Sin embargo, si bien es cierto que los contendidos varían según su contexto socio-histórico y cultural, en el sentido de que para los narradores la influencia africana, o interpretación afrocéntrica, parece no adecuada, la semántica abre otras cosmovisiones, cuyos códigos habría que continuar investigando. Dentro de la polisemia se puede identificar dos momentos: la reproducción de lo negro como lo subversivo, "Ios que hacen los pactos con el Diablo", y la reproducción de estructuras de poder, "los capataces" y "cristos negros", ambas conjugadas y yuxtapuestas a la vez, contradictorias y fragmentadas.

No es el color en sí, es el entorno, las constelaciones, lo que connotan lo bueno y lo malo. Dentro de un pensamiento dual, el Diablo, como fetiche, no solamente "simboliza algunos rasgos importantes de la historia política y económica. ES virtualmente imposible separar la historia social de este símbolo de la codificación simbólica de la historia que lo crea..." (Taussig, 1993; p. 11), que resguarda ambivalencias (malo/bueno), sino va más allá de dicotomías en un lenguaje heterogéneo, expresado en la mitificación.

Por consiguiente, su ausencia no aparece en lo contemporáneo. Así, a la par de representarse como seres fuera de la ley, son personajes fuera del tiempo. De ahí su evocación, la función mítica. El pasado explica el hoy y el ahora mismo; el pasado es pasado, y el hoy es nunca el eterno presente. Si últimamente se ha establecido la correlación entre santos negros y su surgimiento, podemos establecer la correspondencia entre diablos negros, seres diabólicos "fuera de la ley", esto como resultado de la diabolización, como práctica colonial de desvalorizar y marcar la fuerza amenazante de la población de origen africano. Lo extraño es que el no soy yo es sujeto a un proceso de significación que desemboca en la diabolización de lo diferente.

Así, el panteón de la población afrodescendiente y sus expresiones culturales se extiende: a la par de san Benito, cristos negros, san Martín de Porres, evidentemente dentro de las coordenadas del credo cristiano, no deben faltar los diablos negros. Las relaciones y sus significados se están apenas comenzando a entender. Así, la historia oral archivo importante de la memoria histórica- abre caminos y puntos de partida para la reconstrucción del pasado de Ios afrodescendientes en El Salvador, y reconocimiento del inicio de diversas prácticas culturales de la población de origen africano y otras expresiones que bien se pueden denominar afroindígenas.

Con ello, evidenciar ese pasado, difundirlo y asimilarlo como parte de la historia de una nación implica generar una visión multiétnica y multicultural en El Salvador, con el fin de eliminar en la sociedad salvadoreña el racismo, la exclusión, la negación, la intolerancia, transformándolos en la inclusión, el respeto a los derechos humanos, la autodeterminación de Ios afrosalvadoreños; y que, a su vez, se generen políticas orientadas a estos sectores sociales, así como la garantía del cumplimiento de los derechos humanos de las minorías étnicas. 


\section{Referencias}

Albán, A. (2005). Racialización, violencia epistémica, colonialidad lingüística y re-existencia en el proyecto moderno colonial. En: “Debates sobre ciudadanía y políticas raciales en las Américas negras". Editores Claudia Mosquera Rosero-Labbé, Agustín Laó Montes, César Rodríguez Garavito. Bogotá: Universidad Nacional de Colombia. Universidad del Valle,. pp. 197-221.

Bachmann-Medick, D. (2004). Kultur als Text. Die anthropologische Wende in der Literaturwissenschaft. A. Francke Verlag Tübingen und Basel. (Traducción literal del titulo: La cultura como texto. El giro antropológico en los estudios literarios).

Candau, J. (2006). Antropología de la Memoria, Editorial Nueva Visión, Buenos Aires, Argentina.

Castro Varela, M. y Dhawan, N. (2005). Postkoloniale Theorie: eine kritische Einführung. Transcript Verlag. (Traducción literal del título: Teoría Poscolonial: una introducción crítica).

Duncan, Q. (2005). El afrorealismo: una dimensión nueva de la literatura latinoamericana. En: Revista Virtual ISTMO (Julio).

Escalante, P. (1994). Apuntes sobre Mestizaje y Transculturación en las Provincias Hispano-Salvadoreñas. En: Roggenbuck, Stefan (Ed). Cultura y desarrollo en El
Salvador. Konrad-Adenauer-Stiftung. Imprenta Criterio, El Salvador.

Escalante, P. (1995). Apuntes sobre la presencia africana en la historia salvadoreña. En: Anales del Caribe, Centro de Estudios del Caribe, Casa de las Américas. La Habana, Números, 14/15, pp. 83-93. Cuba.

Flores, E. y Masera, M. (Coord.) (2010). Relatos Populares de la Inquisición Novohispana: Rito, Magia y Otras Supersticiones, siglo XVII-XVIII. Unam. México.

Juárez Martínez, A. (2005). Las milicias de lanceros pardos en la región sotaventina durante los últimos años de la colonia. En: Fuerzas Militares en Iberoamérica:

Siglos XVIII y XIX. El Colegio de México, El Colegio de Michoacán, Universidad Veracruzana, México.

Lardé y Larín, J. (2000). El Salvador: historia de sus pueblos, villas y ciudades. Biblioteca de Historia Salvadoreña, Dirección de Publicaciones e Impresos, Concultura, San Salvador, El Salvador.

López Austin, A. (1996). Los Mitos del Tlacuache: Caminos de la Mitología Mesoamericana. Unam, Mexico.

Taussig, M. (1993). El diablo y el fetichismo de la mercancía en Sudamérica. Editorial Nueva Imagen, México.

Vela Peón, F. (2001). Un acto metodológico básico de la investigación social: la entrevista cualitativa. En: María Luisa Tarrés, "Observar, escuchar y comprender sobre la tradición cualitativa en la investigación social". Flacso y el Colegio de México, México. 